\title{
Randomized, Comparative Study of Standard Dose of Rabeprazole versus Omeprazole in Gerd/Heartburn Symptom Relief
}

\author{
Ajayi A.01, Solomon O.A2 , Solomon $0.0^{3}$, Olotu O.S²
}

\author{
${ }^{1}$ Gastroenterology unit, Medicine Department, University Teaching Hospital, Ado Ekiti \\ ${ }^{2}$ Family Medicine Department, Ekiti State University Teaching Hospital, Ado Ekiti \\ ${ }^{3}$ Community Medicine Department, Ekiti State University Teaching Hospital, Ado Ekiti
}

\begin{abstract}
Aim and objective: Gastro-esophageal reflux disease (GERD) is becoming increasingly common in Africa and indeed in Nigeria. Data on the efficacy of proton pump inhibitors in patients with GERD are scanty. In this study, we compared symptom relief rate after first dose treatment with Rabeprazole i.e. $20 \mathrm{mg}$ versus omeprazole $20 \mathrm{mg}$ in GERD/Heart burn patients.
\end{abstract}

\begin{abstract}
Materials and Methods: A total of 66 consenting consecutive patients attending the General Out- Patient Department (GOPD) Clinic of the Ekiti State University Teaching Hospital (EKSUTH), Ado-Ekiti, Nigeria presenting with symptoms of GERD/ heartburn were enrolled for the study. At enrolment, severity of symptom was graded on a five-point scale from none (0), mild (1), moderate (2), severe (3) and very severe (4). After enrolment, the patients were blindly randomized into two groups of 33 each which received either 20mg of Rabeprazole (Barole) stat; Rab- group or 20mg of Omeprazole stat; Ome- group. Symptom status was recorded in Case Report Form (CRF) at enrolment and $1 \mathrm{hr} 30 \mathrm{~min}$ after the treatment with stat dose of the proton pump inhibitor. Efficacy of proton pump inhibitor in symptom relief for GERD/heartburn was assessed by observing the degree of symptom relief after $1 \mathrm{hr} 30$ minutes in each of treatment groups. Approval for the study was obtained from the Ethical and Research Committee of EKSUTH. Informed consent was equally obtained from each of the participants. Data obtained were analyzed using scale of comparison.
\end{abstract}

\begin{abstract}
Results: The mean age of the population studied was aged $33.98 \pm 9.43$ years (age range 18-50 years). 19 (28.8\%) were males while $47(71.2 \%)$ were females (M: F of 1:2.5). $25.8 \%$ of participants had regurgitation as a symptom in addition to heartburn while $40.9 \%$ had other GI symptoms. The mean symptom severity score at baseline were 2.33 , 0.36 and 0.52 for heartburn, regurgitation and other symptoms respectively. Two of the Rabeprazole group who had 'Very severe' heartburn was after $1 \mathrm{hr} 30 \mathrm{mins}$ downgraded to $1(50 \%)$ 'Mild' and $1(50 \%)$ 'Moderate' while only 1 participant with 'very severe' heartburn was downgraded to 'severe' heartburn, $1 \mathrm{hr} 30 \mathrm{mins}$ after Omeprazole.Ten in the Rabeprazole group who presented with 'severe' heartburn were downgraded 4(40\%) to 'moderate' and $6(60 \%)$ 'Mild' heartburn compare with Omeprazole group where 10 of the participants who had 'severe' heartburn were downgraded to $6(60 \%)$ and $4(40 \%)$ with 'moderate' and 'mild' heartburn respectively. One of the participants in Rabeprazole group who had 'Severe' regurgitation was downgraded to 'Nil' regurgitation, while none of the participants in Omeprazole group had 'severe' regurgitation. Two of the participants in Rabeprazole group had other symptoms of 'moderate' severity that were downgraded to 'No symptoms' compared with 5 participants in Omeprazole group with other symptoms with 'moderate severity' out of which 3(60\%) and 2(40\%) were downgraded to 'mild' and 'No symptoms respectively'.
\end{abstract}

Conclusion: Symptomatic relief is one of the primary goals in the management GERD.

In this study Rabeprazole (Barole $\left({ }^{\circledR}\right)$ is more effective in downgrading the heartburn and other symptoms in GERD within 90 minutes of treatment compared to treatment with Omeprazole.

Keywords: GERD, Heart burns, Rabeprazole, Omeprazole and Symptom relief

This article is published under the terms of the Creative Commons Attribution License 4.0 Author(s) retain the copyright of this article. Publication rights with Alkhaer Publications.

Published at: http://www.ijsciences.com/pub/issue/2016-02/

DOI: 10.18483/ijSci.934; Online ISSN: 2305-3925; Print ISSN: 2410-4477 


\section{Introduction}

Gastro-oesophageal reflux disease (GERD) is a common and chronic disorder. Its most common symptom is heartburn, which affects about onequarter of all adults on a regular basis in Western countries $[1,2]$. The disease is not self limiting and pathological reflux in patients with GERD typically persists for years or even decades [3]. GERD is observed to be the most common acid related disorders with prevalence of $20 \%$ among adults in North America and $26.3 \%$ among medical students in Enugu, Nigeria [4-5]. It is a chronic condition characterized by reflux of gastric content into oesophagus with resultant irritation and inflammation of oesophageal mucosa [5].

GERD is commonly associated with several symptoms, such as heartburn, belching, and regurgitation, which results from oesophageal exposure to gastric acid, these symptoms may occur with or without the presence of endoscopically observed oesophageal mucosal damage and inflammation symptoms [6]. Atypical (extra oesophageal) symptoms such as dysphagia, chest pain, laryngitis, GERD induced respiratory and sleep disorders may be seen. GERD could be considered as a spectrum disease, which has milder, non-erosive cases and longer lasting, worse, erosive or complicated cases with deep oesophageal ulcers, stricture or Barrett's oesophagus [6-7].

When treating GERD, the goal of treatment should include not only the healing of mucosal lesions, but also the relief of heartburn symptoms [8-9]. The most effective drugs in treatment of GERD are proton pump inhibitors which produce more complete remission of heartburn symptoms than $\mathrm{H} 2$ receptor antagonists or prokinetic agents $[8,10]$. They are also more effective than $\mathrm{H} 2$ receptor antagonists in promoting healing of oesophageal lesions [8]. In many of the current practice guidelines Proton pump inhibitors are recommended as reasonable for initial treatment for GERD [9]. Rabeprazole since introduction as a proton pump inhibitor has been documented to be effective in treatment of gastric and duodenal ulcers as well as for GERD [11-14].

In this study, we compared symptom relief rate after first dose treatment with rabeprazole i.e. $20 \mathrm{mg}$ versus omeprazole $20 \mathrm{mg}$ in GERD/Heart burn patients.

\section{Methods}

This was a randomized comparative study.

A total of 66 consenting consecutive patients attending the General Out- Patient Departments (GOPD) Clinic of the Ekiti State University Teaching Hospital, Ado-Ekiti, Nigeria presenting with symptoms of GERD/ heartburn were enrolled for the study. At enrolment, severity of symptom was graded on a five-point scale from none (0), mild (1), moderate (2), severe (3) and very severe (4).

After enrolment, the patients were blindly randomized into two groups of 33 each which received either 20mg of Rabeprazole (Barole) stat; Rab- group or $20 \mathrm{mg}$ of Omeprazole stat; Omegroup.

Other upper GI symptoms of belching ('eructation'), early satiety ('the sensation of filling up quickly'), bloating ('feeling like I have a lot of gas in my belly'), nausea and vomiting were also graded on the five-point scale explained above.

Symptom status was recorded in Case Report Form (CRF) at enrolment and $1 \mathrm{hr} 30 \mathrm{~min}$ after the treatment with stat dose of the proton pump inhibitor. Efficacy of proton pump in symptom relief for GERD/heartburn was assessed by observing the degree of symptom relief after $1 \mathrm{hr} 30$ minutes in each of treatment groups.

\section{Results}

\subsection{General Characteristics}

Participants enrolled into the study were aged 18 to 50 years with mean age of $33.98 \pm 9.43$ years. Amongst the participants $19(28.8 \%)$ were males while $47(71.2 \%)$ were females, M: F of $1: 2.5$. $25.8 \%$ of participants had regurgitation as a symptom in addition to heartburn while $40.9 \%$ had other GI symptoms like belching, early satiety, bloating, nausea and vomiting. The mean symptom severity score at baseline were 2.33, 0.36 and 0.52 for heartburn, regurgitation and other symptoms respectively. Table 1 .

\subsection{Efficacy of Rabeprazole Vs Omeprazole 2.1Efficacy of Rabeprazole Vs Omeprazole on Heartburn Relief}

Two of the Rabeprazole group who had 'Very severe' heartburn was after $1 \mathrm{hr} 30 \mathrm{mins}$ downgraded to 1(50\%) 'Mild' and 1 (50\%) 'Moderate' while only 1 participant with 'very severe' heartburn was downgraded to 'severe' heartburn, $1 \mathrm{hr} 30 \mathrm{mins}$ after Omeprazole. (Fig. 1)

Ten of the participants in the Rabeprazole group who presented with 'severe' heartburn were downgraded $4(40 \%)$ to 'moderate' and $6(60 \%)$ 'Mild' heartburn compare with Omeprazole group where 10 of the participants who had 'severe' heartburn were downgraded to $6(60 \%)$ and $4(40 \%)$ with 'moderate' and 'mild' heartburn respectively (Fig. 2).

Of the 20 with 'moderate' heartburn in Rabeprazole group, $16(80 \%)$ and $4(20 \%)$ were downgraded to 'Mild' and 'Nil' (0) heartburn compare to 
Omeprazole group where 19 participants with 'Moderate' heartburn were downgraded with 9 $(47.4 \%)$ and $10(52.6 \%)$ with 'Mild' and 'Nil' heartburn (Fig. 3).

One of the participants in Rabeprazole group had 'Mild' heartburn at presentation and was downgraded to 'Nil' heartburn compared with 3 in the Omeprazole group which had only one of the participants downgraded to 'Nil' heartburn and the remaining 2 were unchanged (Fig. 4).

\subsection{Efficacy of Rabeprazole Vs Omeprazole on Regurgitation}

One of the participants in Rabeprazole group had 'Severe' regurgitation which was downgraded to 'Nil' regurgitation, while none of the participants in Omeprazole group had 'severe' regurgitation (Fig. 5). 3 of those in Rabeprazole group had 'moderate' regurgitation which was downgraded in 1 (33.3\%) and $2(66.7 \%)$ to 'Mild' and 'Nil' regurgitation respectively compare with 2 in Omeprazole group which was downgraded to $1(50 \%)$ each for 'Mild' and 'Nil' regurgitation (Fig. 6). The 5 participants that had 'Mild' regurgitation were downgraded to 'Nil' regurgitation in Rabeprazole group while all 6 that had 'mild' regurgitation were downgraded to 'Nil' regurgitation in Omeprazole (Fig. 7). 24 participants and 25 participants in Rabeprazole and Omeprazole respectively were without regurgitation.

\subsection{Efficacy of Rabeprazole Vs Omeprazole on Other Symptoms}

Two of the participants in Rabeprazole group had other symptoms of 'moderate' severity that were downgraded to 'No symptoms' compared with 5 participants in Omeprazole group with other symptoms with 'moderate severity' out of which $3(60 \%)$ and $2(40 \%)$ were downgraded to 'mild' and 'No symptoms respectively' (Fig. 8). 11 of those in Rabeprazole group has other symptoms with 'mild' severity with $10(90.9 \%)$ downgraded to 'No symptom' while $1(9.1 \%)$ was without improvement and compared with 9 in the Omeprazole group with 'Mild' form of other symptoms, $8(88.9 \%)$ were downgraded to 'No symptom' and $1(11.1 \%)$ was without improvement (Fig. 9). Twenty and 19 of the participants are without 'other symptoms' of GERD in Rabeprazole and Omeprazole group respectively.

\section{Discussion}

Various lifestyle factors are reported to be associated with GERD [15], and reflux symptoms negatively affect health-related quality of life, work productivity, and health resource utilization [16-19]. The severity of GERD is directly correlated with the degree and duration of esophageal acid exposure and is highly $\mathrm{pH}$ dependent [20-22] Moreover, reflux oesophagitis is a risk factor for esophageal stricture in
4-20\% of patients [20], Barrett's esophagus in up to $15 \%$ of patients [21-23] and esophageal adenocarcinoma [24]. Proton pump inhibitors (PPIs) are the most effective treatment for GERD, including endoscopically confirmed reflux oesophagitis [25]. Most individuals experience resolution of their reflux symptoms when taking a PPI [25], with a concomitant overall improvement in health-related quality of life [26-27].

Rabeprazole has been documented to have a faster onset of antisecretory action than Omeprazole. In this study we observed that Rabeprazole achieved a more rapid downgrading of heartburn within the $1^{\text {st }}$ one and half hour of ingestion compared with Omeprazole and other symptoms in GERD within 90 minutes of treatment compared to treatment with Omeprazole this is comparable to the observation by Adachi $\mathrm{K}$ e $\mathrm{t}$ al where downgrading of severity of heartburn amongst patients with erosive reflux oesophagitis was more rapid in Rabeprazole compared to Omeprazole group [28] similar study of symptomatic relief by Rabeprazole and Omeprazole amongst participants with erosive GERD related heartburn by Xia and Wang favoured Rabeprazole 20 $\mathrm{mg}$ over Omeprazole $20 \mathrm{mg}$ for relief of heartburn $(\mathrm{RR}=1.133 ; 95 \% \mathrm{CI}: 1.028-1.249 ; \mathrm{P}=0.012)$ [29], while a multicenter study done by Sloan in United states observed significant positive effect of $10 \mathrm{mg}$ of Rabeprazole on heartburn and other GERD symptoms like regurgitation, belching, bloating, early satiety, and nausea within 1 and 2 days compare to 20 $\mathrm{mg}$ of Omeprazole, this study observed significant effect using $20 \mathrm{mg}$ of Rabeprazole on heartburn, regurgitation and other symptoms of GERD within 90 mins of administration when compared with Omeprazole [30].

PPIs are metabolized via the hepatic enzyme cytochromes P450, 2C19 and CYP2C19. There are three genetic polymorphisms of CYP2C19, resulting in homozygous extensive metabolizer (homoEM), heterozygous extensive metabolizer (heteroEM) and poor metabolizer (PM) phenotypes [31]. These CYP2C19 phenotypes have different effects on the pharmacodynamic and pharmacokinetic profiles of PPIs. Gastric acid secretion is affected such that postPPI intragastric $\mathrm{pH}$ values are highest in the PM group and lowest in the homoEM group following administration of omeprazole or Rabeprazole [32]. The clinical relevance of these differences is especially important for patients in Japan, where the PM phenotype is much more common (prevalence 18.0-22.5\%) than in the USA or Europe (prevalence $\leq 3.7 \%)[31]$.

Results obtained from this study are similar to that obtained in the studies among healthy Japanese volunteers where the different CYP2C19 phenotypes 
were taken into consideration [33-35]. Compared with omeprazole $20 \mathrm{mg}$ or lansoprazole $30 \mathrm{mg}$, rabeprazole $10 \mathrm{mg}$ has been shown to exert a faster and more pronounced inhibition of gastric acid secretion in these healthy Japanese volunteers with the homoEM or heteroEM phenotypes [33]. The findings in this study were in contrast to that obtained in the study of Nagahara et al where omeprazole $20 \mathrm{mg}$ was found to be more effective than Rabeprazole $10 \mathrm{mg}$ at achieving early, sufficient, sustained reflux symptom relief in individuals with the CYP2C19 PM phenotype, and is similarly effective to rabeprazole $10 \mathrm{mg}$ in those with heteroEM or homoEM phenotypes [36].

Conclusion: Symptomatic relief is one of the primary goals in the management GERD.

In this study Rabeprazole (Barole $\AA$ ) is more effective in downgrading the heartburn and other symptoms in GERD within 90 minutes of treatment compared to treatment with Omeprazole.

Table 1: General characteristics of the population

\section{General Characteristics}

\begin{tabular}{|ll|}
\hline Sex & \\
Male & $19(28.8 \%)$ \\
Female & $47(71.2 \%)$ \\
Age & $35.23 \pm 12.27 \mathrm{yrs}$ \\
Weight & $65.62 \pm 12.8 \mathrm{Kg}$ \\
Mean Symptom Score at Presentation & \\
Heart Burns & $2.33 \pm 0.66$ \\
Regurgitation & $0.36 \pm 0.69$ \\
Other symptoms & $0.52 \pm 0.69$ \\
Duration of symptoms prior presentation & $19.5 \pm 28.2$ months \\
Associated mobility & \\
Diabetes & \\
Yes & $0(0 \%)$ \\
No & $66(100 \%)$ \\
Hypertension & \\
Yes & $7(10.6 \%)$ \\
No & $59(89.4 \%)$ \\
\hline
\end{tabular}


Randomized, Comparative Study of Standard Dose of Rabeprazole versus Omeprazole in Gerd/Heartburn Symptom Relief

Fig. 1 Effectiveness of Rabeprazole vs. Omeprazole in Very Severe Heartburn

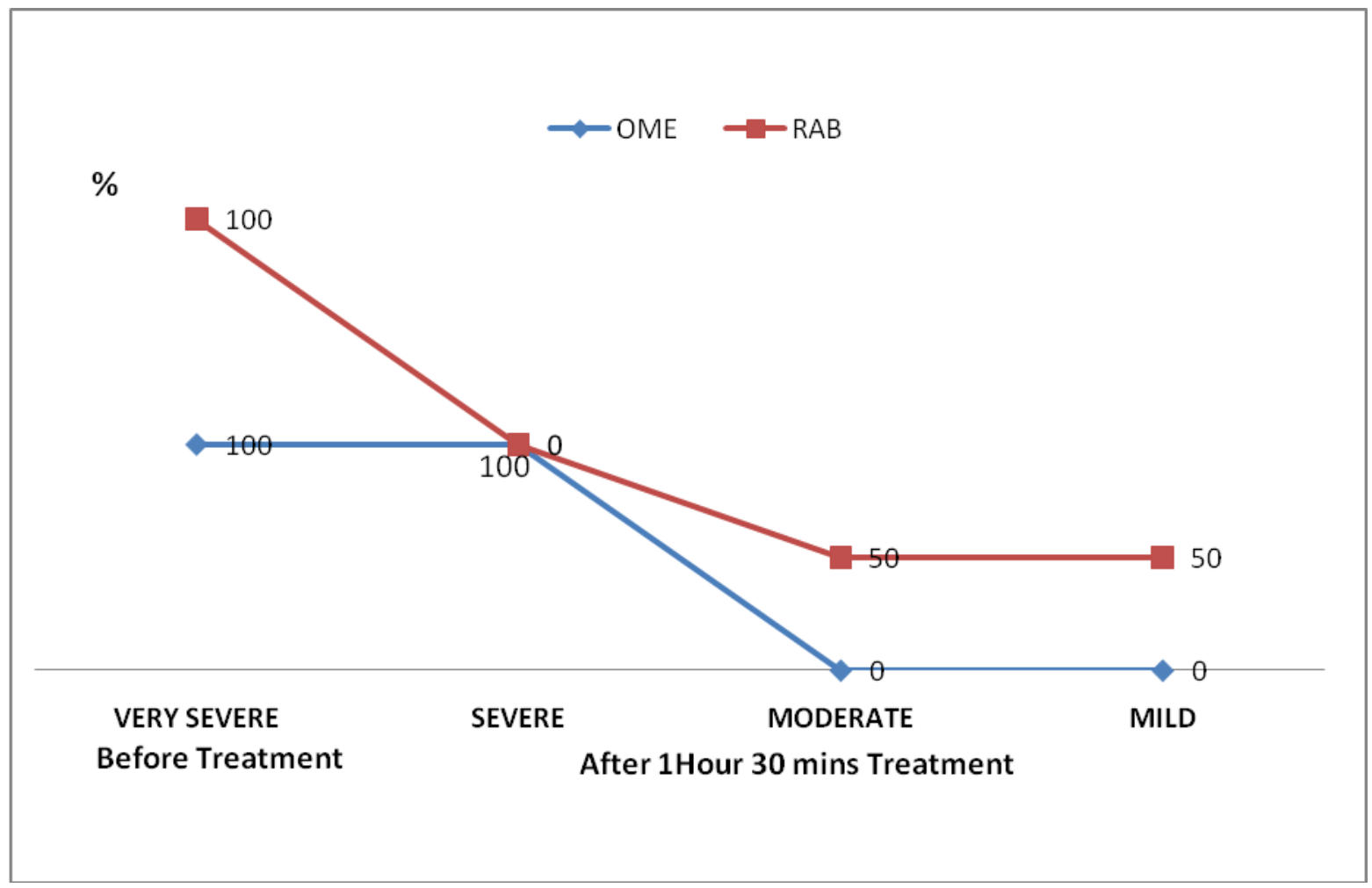

Fig.2 Effect of Rabeprazole Vs. Omeprazole in Severe Heartburn

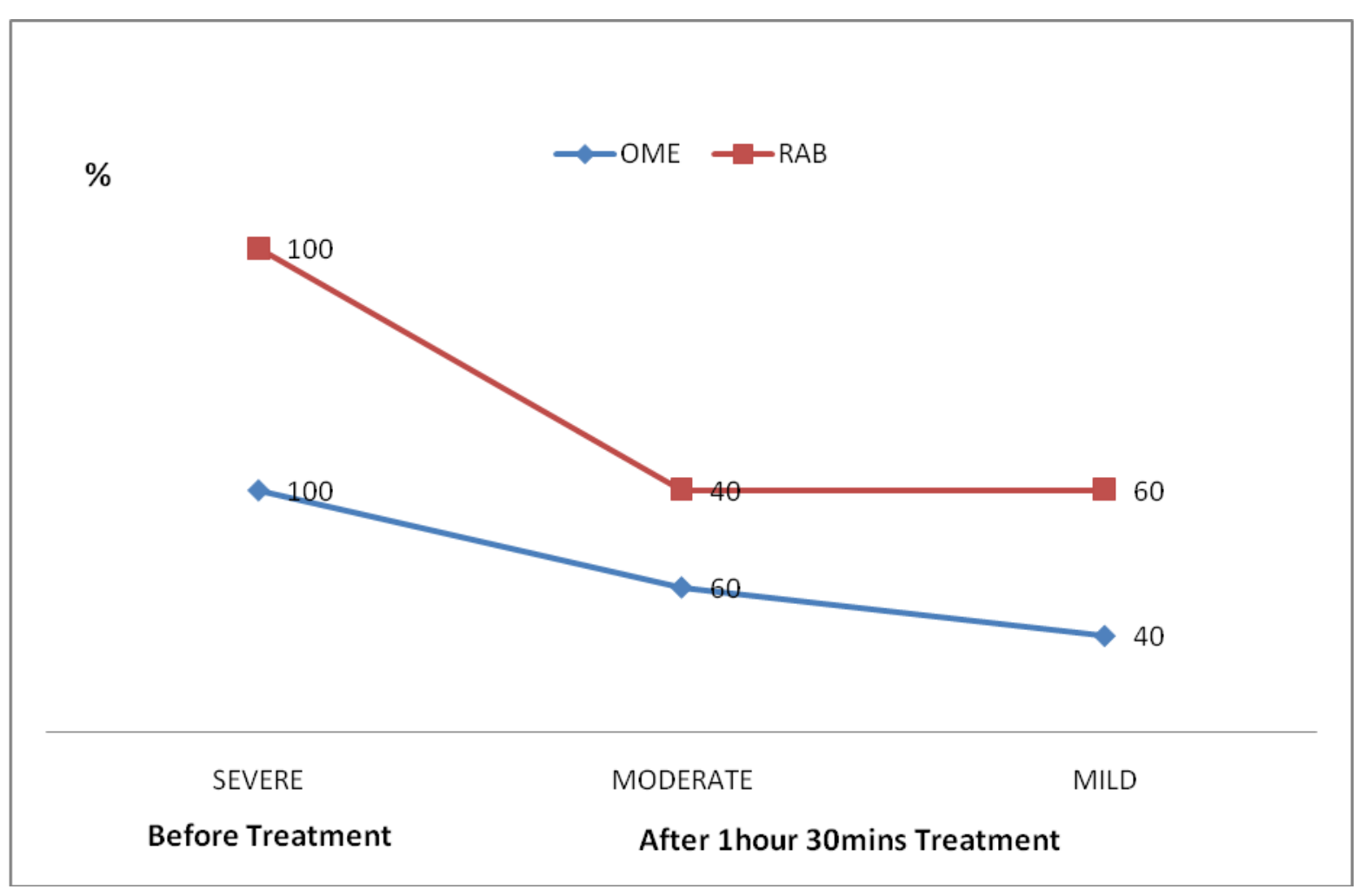


Randomized, Comparative Study of Standard Dose of Rabeprazole versus Omeprazole in Gerd/Heartburn Symptom Relief

Fig. 3 Effectiveness of Rabeprazole Vs. Omeprazole in Moderate Heartburn

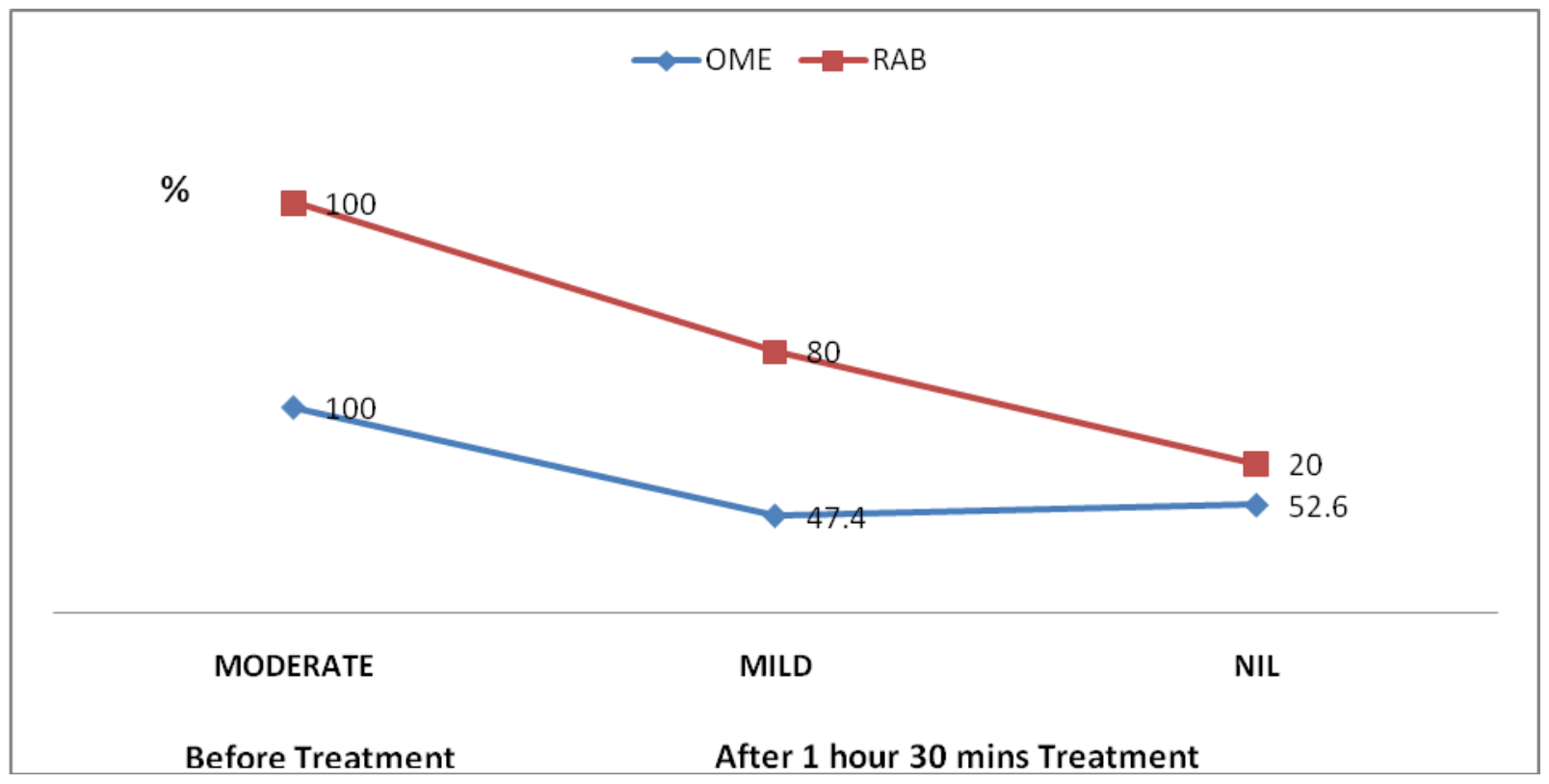

Fig. 4 Effectiveness of Rabeprazole Vs Omeprazole in Mild Heartburn

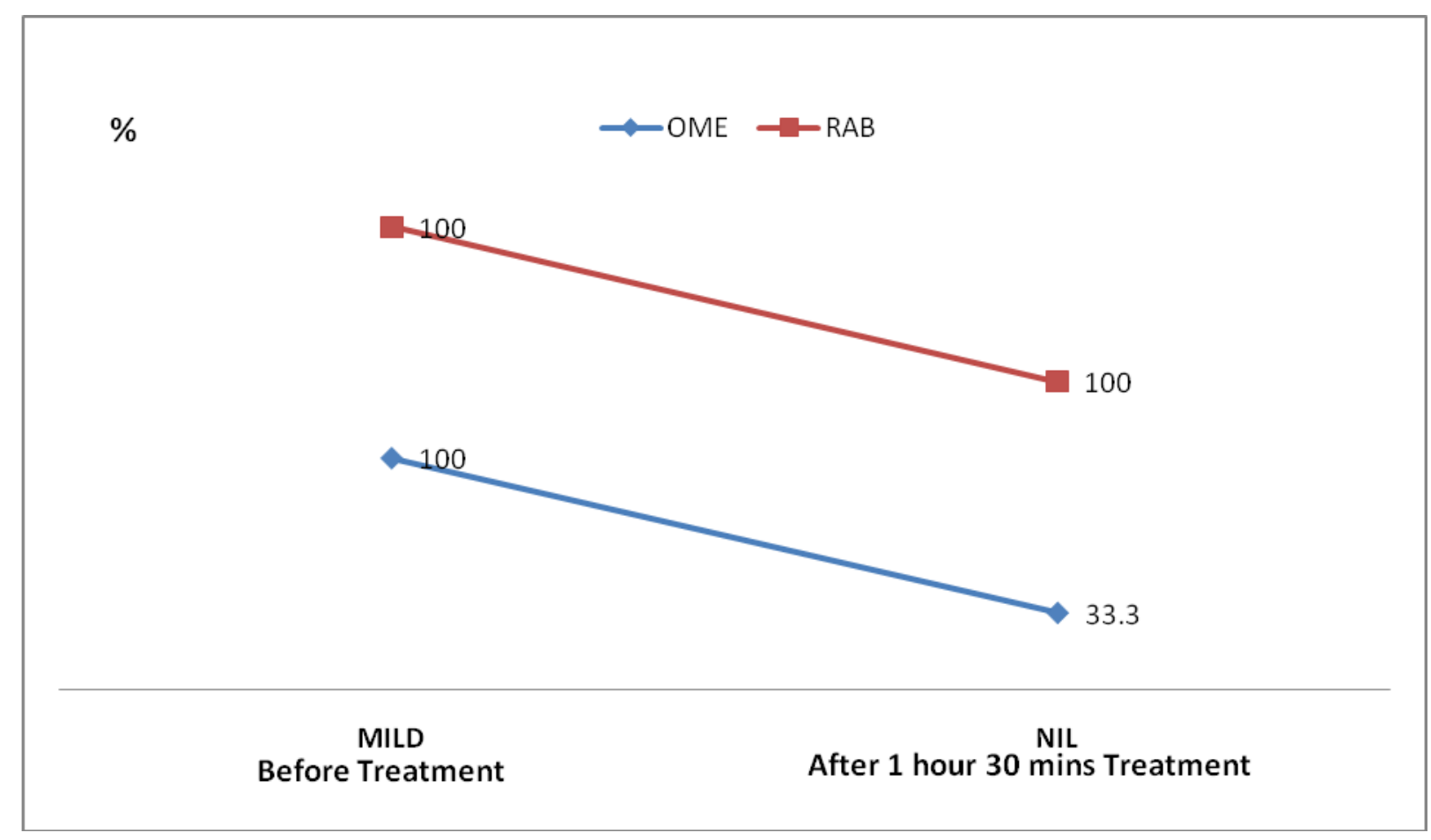


Randomized, Comparative Study of Standard Dose of Rabeprazole versus Omeprazole in Gerd/Heartburn Symptom Relief

Fig. 5 Effectiveness of Rabeprazole Vs Omeprazole in Severe Regurgitation

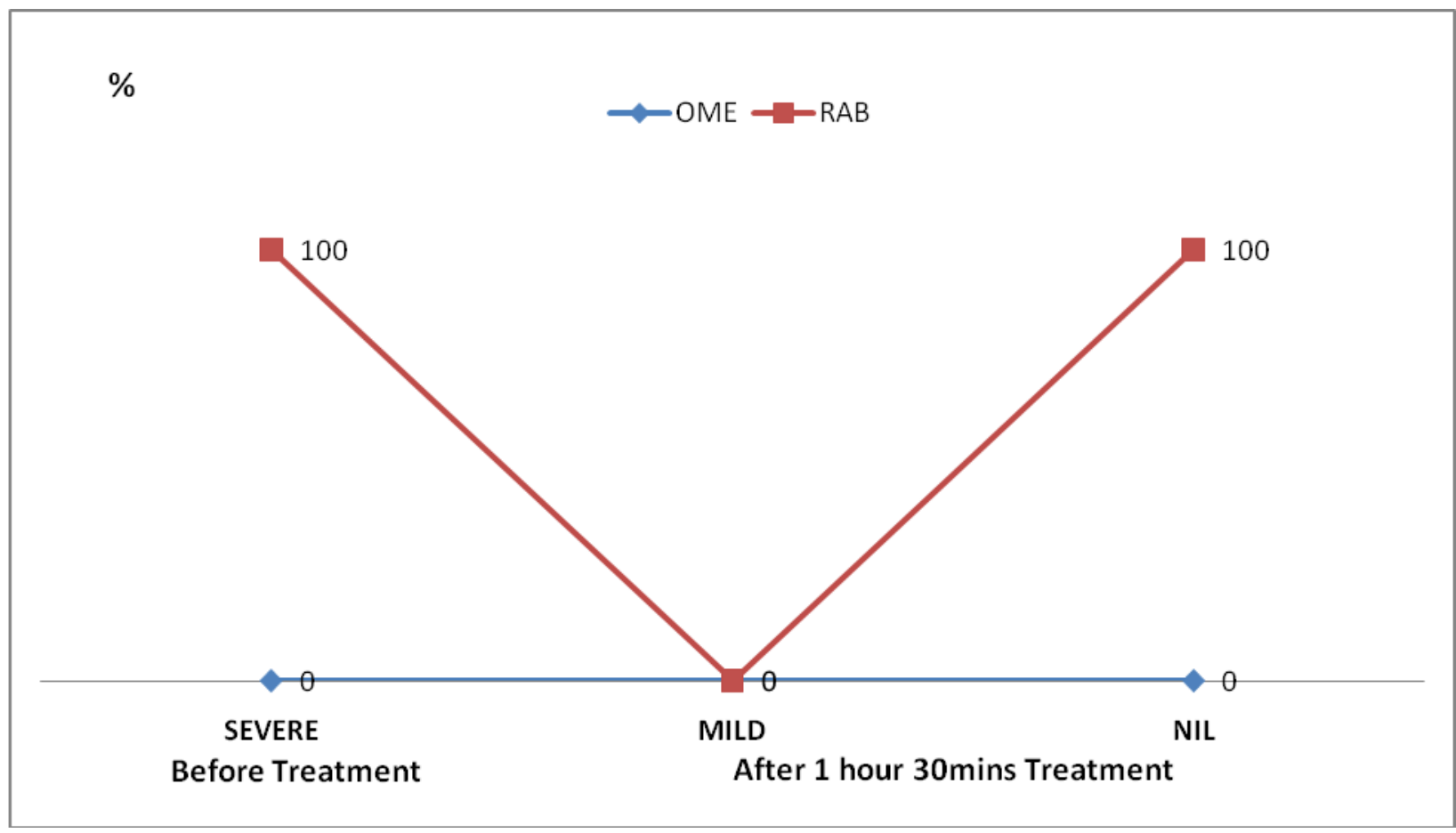

Fig 6. Effectiveness of Rabeprazole Vs Omeprazole in Moderate Regurgitation

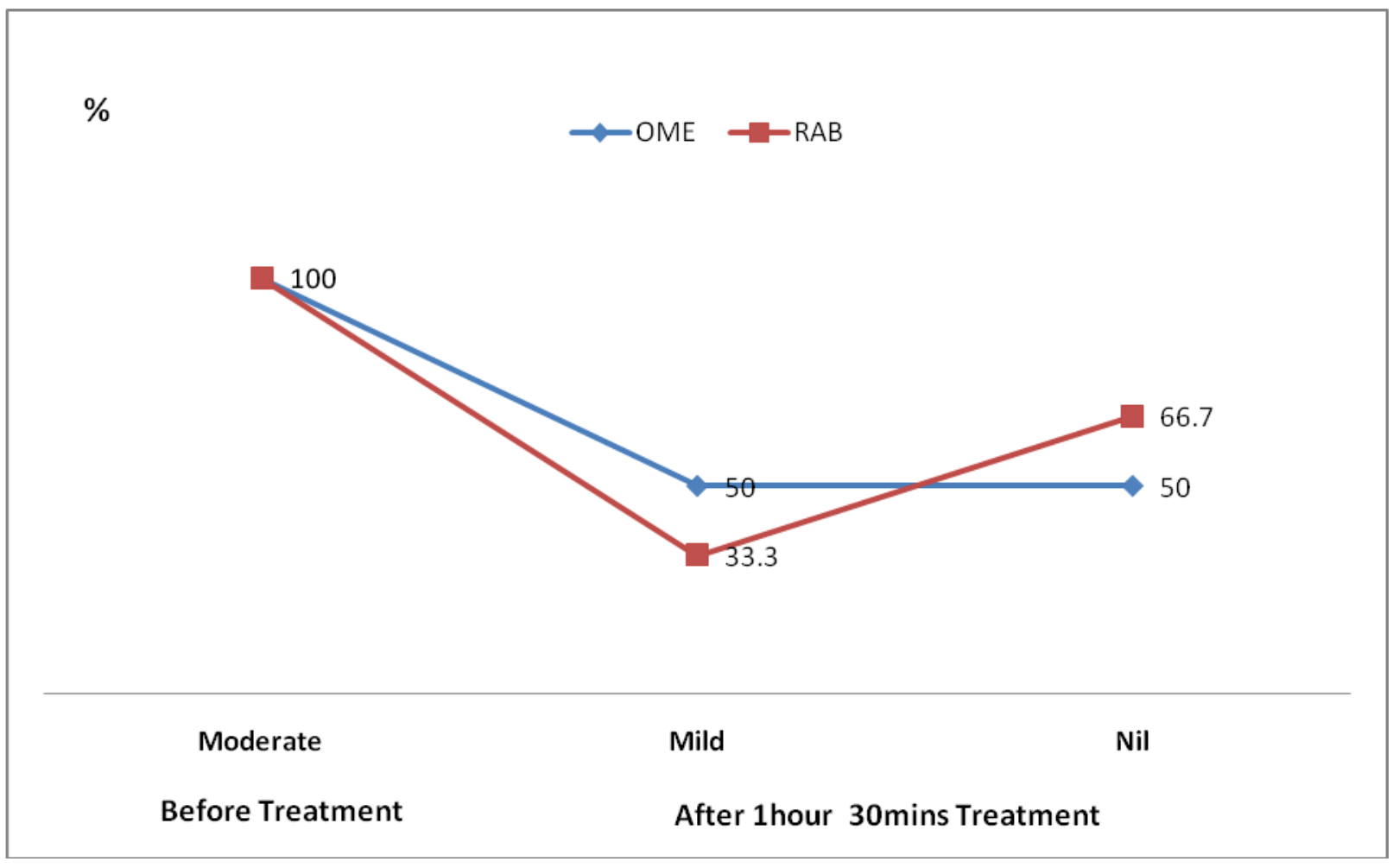


Randomized, Comparative Study of Standard Dose of Rabeprazole versus Omeprazole in Gerd/Heartburn Symptom Relief

Fig. 7 Effectiveness of Rabeprazole Vs Omeprazole in Mild Regurgitation

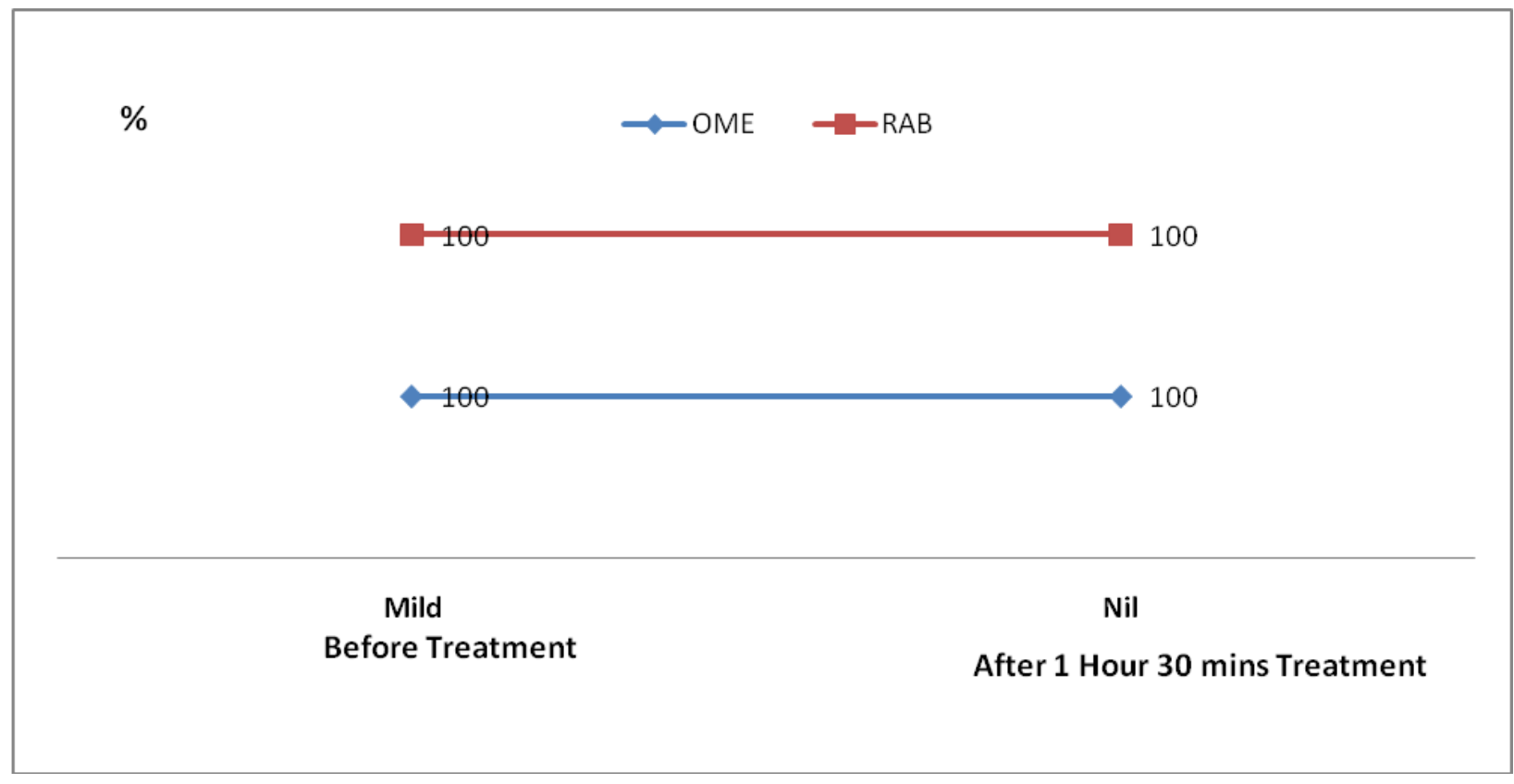

Fig. 8 Effectiveness of Rabeprazole Vs. Omeprazole in Moderate Other GERD Symptoms

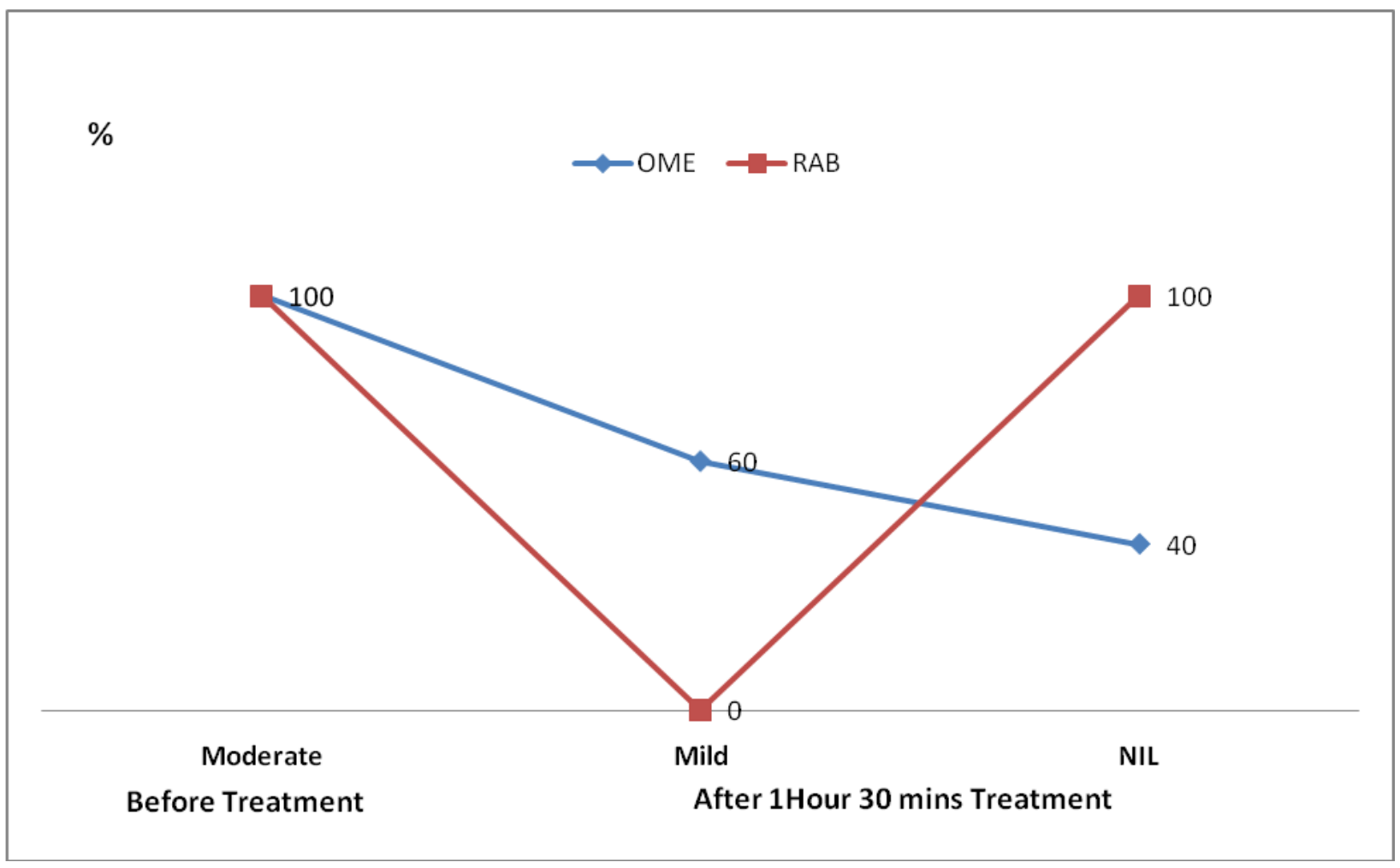


Fig. 9 Effectiveness of Rabeprazole Vs. Omeprazole in Mild Other GERD Symptoms

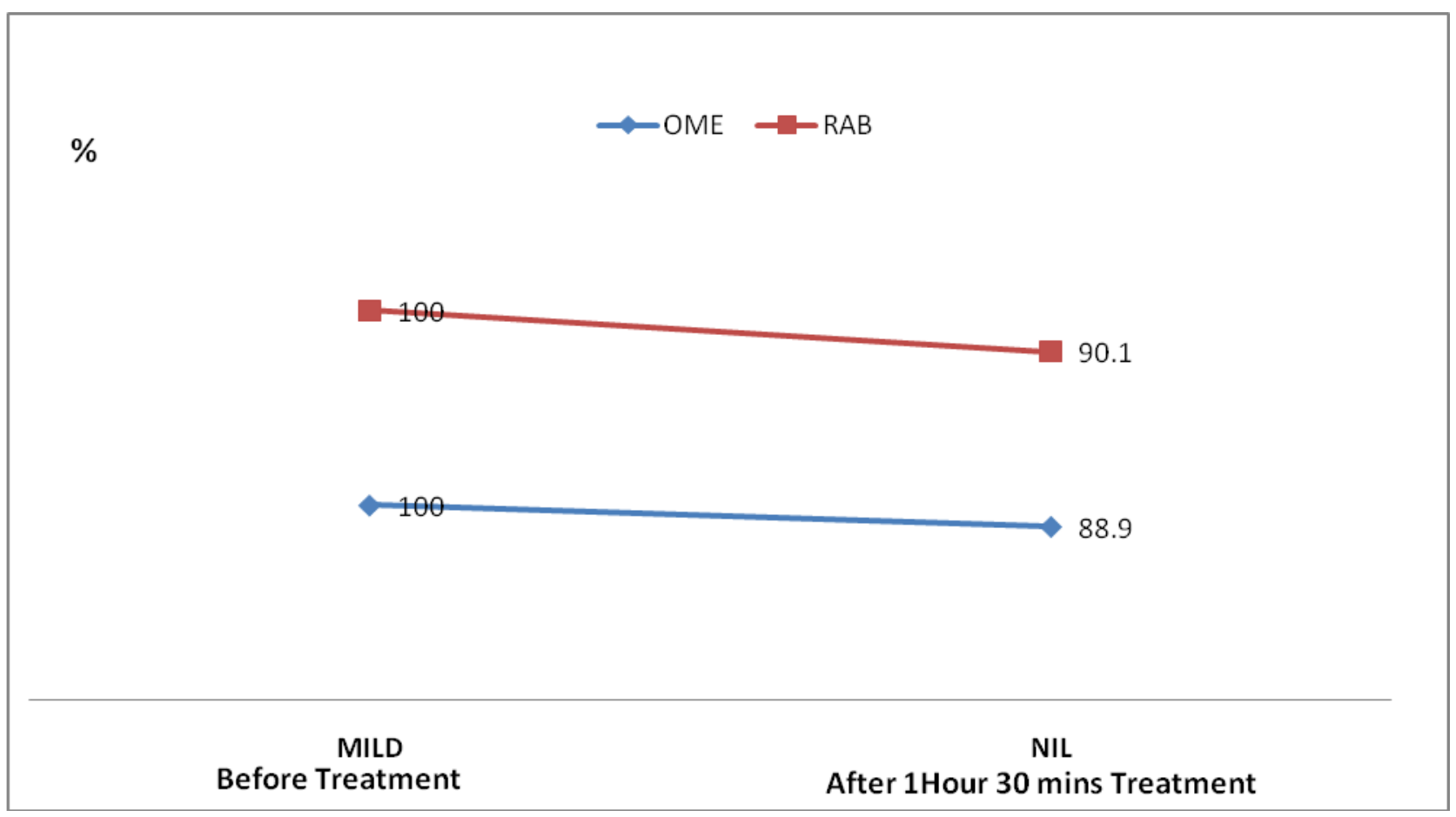

\section{References:} 2. patients with these symptoms. Aliment Pharmacol Ther 2000;

3. Van Pinxteren B, Numans ME, Bonis PA, Lau J. Short-term treatment with proton pump inhibitors, H2-receptor antagonists and prokinetics for gastro-oesophageal reflux disease like symptoms and endoscopy negative reflux disease (Cochrane Review). Cochrane Database Syst Rev 2000, 2: CD002095.

4. Isolauri J, Luostarinen M, Isolauri E, Reinikainen P, Viljakka M, Keyrilainen O. Natural course of gastroesophageal reflux disease: $17 \pm 22$ year follow-up of 60 patients. Am J Gastroenterol 1997; 92: 37- 41

5. Nwokediuko S. Gastroesophageal reflux disease: a population based study. Gastroenterol Res. 2009;2:152-156

6. Robinson M, Fitzgerald S, Hegedus R, et al. Onset of symptom relief with rabeprazole: a community-based, openlabel assessment of patients with erosive oesophagitis. Aliment Pharmacol Ther 2002; 16: 445-454.

7. Pace F, Pallota S, Casalini S, et al. A review of rabeprazole in the treatment of acid related diseases. Therapeutics and Clinical Risk Management 2007:3(3) 363-379

8. Farley A, Wruble LD, Humphries TJ. Rabeprazole versus ranitidine for the treatment of erosive gastroesophageal reflux disease: a double-blind, randomized clinical trial. Rabeprazole Study Group. Am J Gastroenterol 2000; 95: 1894-1899

9. DeVault KR. Overview of medical therapy for Gastroesophageal reflux disease.

Gastroenterol Clin NorthAm1999; 28: 831-845.

10. DeVault KR, Castell DO. Updated guidelines for the diagnosis and treatment of gastroesophageal reflux disease. Am J Gastroenterol 1999; 94: 1434-1442

11. Van Pinxteren B, Numans ME, Bonis PA, Lau J. Short-term treatment with proton pump inhibitors, H2-receptor antagonists and prokinetics for gastro-oesophageal reflux disease like symptoms and endoscopy negative reflux disease

\section{After 1 Hour 30 mins Treatment}

mptoms in a UK population and the consultation behaviour of (Cochrane Review). Cochrane Database Syst Rev 2000, 2: CD002095.

12. Prakash A, Faulds D. Rabeprazole. Drugs 1998; 55: 261-7. Dekkers CP, Beker JA,

13. Thjodleifsson B, Gabryelewicz A, Bell NE, Humphries TJ. Double-blind, placebo-controlled comparison of rabeprazole $20 \mathrm{mg}$ vs. omeprazole $20 \mathrm{mg}$ in the treatment of erosive or ulcerative gastro-oesophageal reflux disease. Aliment Pharmacol Ther 1999; 13: 49-57.

14. Robinson MG, Maton PN, Rodriguez S, Greenwood B, Humphries TJ. Effects of oral rabeprazole on oesophageal and gastric $\mathrm{pH}$ in patients with gastro-oesophageal reflux disease. Aliment Pharmacol Ther 1997; 11: 973-980.

15. Cloud ML, Enas N, Humphries TJ, Bassion S. Rabeprazole in treatment of acid peptic diseases: results of three placebo controlled dose-response clinical trials in duodenal ulcer, gastric ulcer, and gastroesophageal reflux disease (GERD). Dig Dis Sci 1998; 43: 993-1000.

16. Matsuki N, Fujita T, Watanabe N, et al. Lifestyle factors associated with gastroesophageal reflux disease in the Japanese population. J Gastroenterol. 2013;48: 340-349.

17. Ronkainen J, Aro P, Storskrubb T, et al. Gastro-oesophageal reflux symptoms and health-related quality of life in the adult general population - the Kalixanda study. Aliment Pharmacol Ther. 2006; 23: 1725-1733.

18. Wahlqvist P, Reilly M, Barkun AN. Systematic review: the impact of gastro-oesophageal reflux disease on work productivity. Aliment Pharmacol Ther. 2006; 24:259-272.

19. Wahlqvist P, Karlsson M, Johnson D, Carlsson J, Bolge S, Wallander MA. Relationship between symptoms of gastroesophageal reflux disease and costs: a database study in a US cohort. Value Health. 2007; 10:A149.

20. Wiklund I, Carlsson J, Vakil N. Gastroesophageal reflux symptoms and well-being in a random sample of the general population of a Swedish community. Am J Gastroenterol. 2006; 101: 18-28.

21. Spechler SJ. Epidemiology and natural history of gastroesophageal reflux disease. Digestion 1992; 51 Suppl 1: 


\section{4-29}

22. Orlando RC. The pathogenesis of gastroesophageal reflux disease: the relationship between epithelial defense, dysmotility, and acid exposure. Am J Gastroenterol 1997; 92: 3S-5S; discussion 5S-7S

23. Johnston BT, Collins JS, McFarland RJ, Love AH. Are esophageal symptoms reflux-related? A study of different scoring systems in a cohort of patients with heartburn. Am J Gastroenterol 1994; 89: 497-502

24. Winters C Jr, Spurling TJ, Chobanian SJ, Curtis DJ, Esposito RL, Hacker JF 3rd, Johnson DA, Cruess DF, Cotelingam JD, Gurney MS. Barrett's esophagus. A prevalent, occult complication of gastroesophageal reflux disease. Gastroenterology 1987; 92: 118-124

25. Ronkainen J, Talley NJ, Storskrubb T, et al. Erosive esophagitis is a risk factor for Barrett's esophagus: a community-based endoscopic follow-up study. Am J Gastroenterol. 2011; 106:1946-1952.

26. van Pinxteren B, Numans ME, Bonis PA, Lau J. Short-term treatment with proton pump inhibitors, H2-receptor antagonists and prokinetics for gastro-oesophageal reflux disease-like symptoms and endoscopy negative reflux disease. Cochrane Database Syst Rev. 2004;4 :CD002095.

27. Kulig M, Leodolter A, Vieth M, et al. Quality of life in relation to symptoms in patients with gastro-oesophageal reflux disease - an analysis based on the ProGERD initiative. Aliment Pharmacol Ther. 2003; 18:767-776.

28. Pace F, Negrini C, Wiklund I, Rossi C, Savarino V. Quality of life in acute and maintenance treatment of non-erosive and mild erosive gastro-oesophageal reflux disease. Aliment Pharmacol Ther. 2005; 22:349-356.

29. Adachi K, Hashimoto T, Hamamoto N, et al., "Symptom relief in patients with reflux esophagitis: comparative study of omeprazole, lansoprazole, and rabeprazole," Journal of Gastroenterology and Hepatology, vol. 18, no. 12, pp. 13921398, 2003.
30. Xia X M, Wang H. Gastroesophageal reflux disease relief in patients treated with Rabeprazole $20 \mathrm{mg}$ versus Omeprazole $20 \mathrm{mg}$ : a meta analysis. Gastroenterology Research and practice. Hindawi Publishing Company 2013 http://dx.doi.org/10.1155/2013/327571, accessed on 28/03/2015

31. Sloan S. 2003. Rabeprazole-based therapy in the management of symptomatic gastroesophageal reflux disease. Am J Gastroenterol, 98(3 Suppl): S49-S55.

32. Furuta T, Sugimoto M, Shirai N, Ishizaki T. CYP2C19 pharmacogenomics associated with therapy of Helicobacter pylori infection and gastro-esophageal reflux diseases with a proton pump inhibitor. Pharmacogenomics. 2007; 8:11991210.

33. Shirai N, Furuta T, Moriyama Y, et al. Effects of CYP2C19 genotypic differences in the metabolism of omeprazole and Rabeprazole on intragastric $\mathrm{pH}$. Aliment Pharmacol Ther. 2001; 15: 1929-1937.

34. Saitoh T, Fukushima Y, Otsuka H, et al. Effects of rabeprazole, lansoprazole and omeprazole on intragastric $\mathrm{pH}$ in CYP2C19 extensive metabolizers. Aliment Pharmacol Ther. 2002; 16: 1811-1817.

35. Yamagishi H, Koike $\mathrm{T}$, Ohara S, et al. Early effects of Lansoprazole orally disintegrating tablets on intragastric $\mathrm{pH}$ in CYP2C19 extensive metabolizers. World J Gastroenterol. 2008; 14:2049-2054.

36. Furuta K, Adachi K, Ohara S, et al. Relationship between the acid-inhibitory effects of two proton pump inhibitors and CYP2C19 genotype in Japanese subjects: a randomized twoway crossover study. J Int Med Res. 2010; 38: 1473-1483.

37. Nagahara A, Suzuki T, Nagata N, Sugai N, Takeuchi Y, Sakurai K, Miyamoto M,et al. A multicentre randomised trial to compare the efficacy of omeprazole versus rabeprazole in early symptom relief in patients with reflux esophagitis. J Gastroenterol (2014) 49:1536-1547. DOI 10.1007/s00535013-0925-8 